\title{
1
}

\section{Is There a Link Between Corporate Purpose and Performance?}

\begin{abstract}
After 50 years of debate on this crucial question, the evidence is increasingly strong in favor of "yes": companies can achieve better results if they incorporate practices that foster people's sense of purpose. This relationship seems to be valid for very different types of industries and various business strategies within the cost-differentiation spectrum. However, causality between purpose and performance is not as linear as some literature and consultants seem to indicate. In this chapter, we discuss this relationship under the perspective of unity (the degree of mutual trust and commitment to the company experienced by people who contribute to fulfilling its purpose). Based on this perspective, we provide a framework that distinguishes four types of cultures: bureaucratic, paternalistic, aggressive and competent.
\end{abstract}

Keywords Purpose $\bullet$ Unity $\bullet$ Culture $\bullet$ Engagement $\bullet$ Management by missions

The sponsors are: DPMC Foundation \& Chair in Management by Missions and Corporate Purpose (UIC) 
After 50 years of debate on this crucial question, the evidence is increasingly strong in favor of "yes." In the well-known study "Corporate Purpose and Financial Performance," Gartenberg, Prat and Serafeim demonstrate, with a large data sample from more than 900 companies and half a million employees, that companies can achieve better results if they incorporate practices that foster people's sense of purpose. This result seems to be valid for very different types of industries and for a wide variety of companies-from manufacturing companies to service organizations - and for various business strategies within the cost-differentiation spectrum.

It is not the only study to demonstrate this. In recent decades, Gallup studies show that when companies engage their employees and customers, they experience a $240 \%$ boost in performance compared to companies where neither their employees nor their customers are engaged. ${ }^{2}$ Similar conclusions in Julian Birkinshaw's studies show the reinforcement between purpose and profit in long-lasting companies, such as HCL Technologies, IKEA, LEGO Group, Novo Nordisk, Roche, Tata Group, Whole Foods Market and W.L. Gore \& Associates. ${ }^{3}$ This evidence leads us to conclude that a company's performance and long-term survival both depend, to a large extent, on the type and depth of its members' commitment. This idea is not new, but never before has it been such a differentiator. In the digital age, it is vital to have committed talent to successfully compete in an environment characterized by uncertainty, hyper-competitiveness and constant change. In addition, this talent is increasingly liquid: it is not tied to a geography, nor to a job for life. Talent appears and disappears at the blink of an eye, causing a real battle for recruiting and retaining the cream of the crop.

Thus, the impact of managerial decisions on employee engagement is in the spotlight like never before. HR departments are embracing the marketing mindset and metrics to evaluate company reputation (a.k.a. employer branding) and employee experience. Companies as diverse as

\footnotetext{
${ }^{1}$ C. Gartenberg, A. Prat and G. Serafeim, "Corporate Purpose and Financial Performance," Organization Science, vol. 30, no. 1, 2019, pp. 1-18.

${ }^{2}$ See: https://news.gallup.com/businessjournal/176063/five-ways-top-performing-companies-engagecustomers.aspx. [Referenced: 11/11/2020]

${ }^{3}$ J. Birkinshaw, N.J. Foss and S. Lindenberg, "Combining Purpose with Profits," MIT Sloan Management Review, vol. 55, no. 3, 2014, p. 49.
} 
Unilever and IBM are putting all their knowledge of artificial intelligence and digital technology at the service of employees. They realize their own continuity depends on it.

Generational changes are also acting as a catalyst to purpose. Millennials (born in the 1990s) and centennials (a.k.a. Gen Z, in the early twentyfirst century), in addition to being digital natives, have emerged with a very different set of values and outlook on work compared to previous generations. One important value, derived from their virtual experience, is flexibility. The new talent avoids rigid hours and working in a fixed office. In their world, there is no point in "going to work," when they can work perfectly well without "going" anywhere.

In addition to flexibility, new talent aspires to contribute by working for companies with sustainable values. This is well known by companies that focus on employer branding, and they need to adjust their objectives and their messaging to project the company as a socially responsible entity with sustainable values. William Pollard, President of ServiceMaster, expressed this idea in the following terms: "If we focused exclusively on profit, we would be a firm that had failed to nurture its soul." ${ }^{4}$

\section{Unity: The Bottom Line of Corporate Culture}

Every managerial decision inevitably has an external consequence as far as greater or lesser economic benefit, along with an internal consequence as far as strengthening or weakening people's commitment. In addition, we have seen how employee commitment ultimately influences the company's profitability. Thus, decisions based on just one variable (such as profit) are lacking, if not dangerous for the company's operation and survival.

Economic performance has a clear control parameter: profit, which can be measured in many ways (ROI, ROE, profit on sales, etc.). This parameter is quite useful for making decisions and evaluating management performance. For generations, budgets have served managers as a guide to making decisions on all types of investments and expenses. However, the cultural dimension is difficult to assess, precisely because it

\footnotetext{
${ }^{4}$ ServiceMaster Annual Report, Downers Grove, Illinois, 2. Cited in Pfeffer, op. cit., 1998, p. 298.
} 
lacks a clear measurement parameter. Many managers rightly wonder: is it possible to have a parameter that covers such a complicated and subjective dimension?

At first glance, it may seem like there are too many things that affect people's behaviors in a company. Fortunately, the vast majority of studies on this topic reach the same conclusion: the mutual trust and commitment of employees toward the company constitute the root and essence of the cultural dimension. These two elements are mutually reinforcing; one cannot exist without the other, as they are essentially two sides of the same coin, which we call "unity." Unity begins with those "inside," the members of the organization, and expands "out," creating strong and lasting relationships between the company and its stakeholders.

Unity is necessary for the life of any organism or social organization and is not to be confused with rigidity toward change, or with uniformity. A uniform body is most often a dead body. Living organisms are made up of very diverse members, which interact continuously, providing the various inputs required to achieve a common goal: diversity and interdependence are necessary conditions for true unity, and unity is a condition of life. When an organism loses unity, it starts to decompose. That is why long-lived companies typically have a high degree of unity.

We define unity as the degree of mutual trust and commitment to the company experienced by people who contribute to fulfilling its purpose. This definition applies to any level of the company: division, department or group; it can even include external stakeholders, such as customers, partners or suppliers. Companies with a high degree of unity are known by a variety of names in management literature: "excellent companies,"5 "high-trust organizations,"6 "citizen corporations," "the individualized corporation," "conscious companies," "purpose-driven organizations" 10

\footnotetext{
${ }^{5}$ T. Peters and R. Waterman, In Search of Excellence, op. cit.

${ }^{6}$ R.B. Shaw, Trust in the Balance, Josey-Bass Publishers, San Francisco, 1997.

${ }^{7}$ C. Handy, "The Citizen Corporation," Harvard Business Review, vol. 75, no. 5, 1997, pp. $26-27$.

${ }^{8}$ S. Ghosal and C.A. Bartlett, The Individualized Corporation, Harper Business, New York, 1997.

${ }^{9}$ J. Mackey and R. Sisodia, Conscious Capitalism: Liberating the Heroic Spirit of Business, Harvard Business Review Press, Boston, MA, 2014.

${ }^{10}$ C. Rey, M. Bastons and P. Sotok, Purpose-Driven Organizations: Management Ideas for a Better World, Springer Nature, London, 2019, p. 138.
} 
and so on. With slight variations in emphasis, all these companies have policies that increase their employees' mutual trust and commitment. Thus, unity can be seen as a precise and useful "bottom line" for cultural performance: a simple criterion for us to assess the effectiveness of management decisions in this dimension.

Although there is no standard measure of unity, there are various measures of assessing it. One way is in terms of "organizational commitment."11 Fortune magazine uses a measure called "The Great Place to Work Trust Index" to distinguish the top 100 American companies in terms of employees' trust in management, pride in their company and camaraderie. This comes fairly close to what we call "unity."

\section{Unity and Survival}

The companies ranked among Fortune's 100 Best Companies to Work For have high levels of unity. According to Arie de Geus, that makes them good candidates to survive longer than other companies in the same competitive environment. ${ }^{12}$ Companies with high levels of unity are better able to adapt to changes in the environment, because it takes trust to foster individual initiative, knowledge transfer and organizational learning - all the things on which any organizational change depends.

That is confirmed in the studies by Douglas and Truelove on the way companies like Sephora, Four Seasons and Danone North America recovered quickly from the loss of profits during the financial crisis of 2007. The key was to maintain and reinforce people's commitment through credibility and leadership, and build a high degree of unity throughout the organization. How did they do it? Rather than focus solely on profit, their employees collaborated to create a common purpose that superseded individual goals and represented the key element in overcoming the crisis. ${ }^{13}$

\footnotetext{
${ }^{11}$ J.P. Meyer and N.J. Allen, Commitment in the Workplace: Theory, Research, and Application, Sage Publications, Thousand Oaks, CA, 1997.

${ }^{12}$ A.D. Geus, The Living Company: Habits for Survival in a Turbulent Business Environment, Harvard Business Review Press, Boston, MA, 1997.

${ }^{13}$ D.A. Ready and E. Truelove, "The Power of Collective Ambition," Harvard Business Review, December 2011.
} 
We are seeing the same strategy with the current COVID-19 crisis: companies such as Microsoft, Google and Disney are making great efforts to avoid layoffs and keep their people committed and engaged. Starbucks has extended its mental health benefits to support employees during the crisis. ${ }^{14}$ These and many other examples show that companies are not motivated exclusively by economic factors, not even in the long term. Because the long term only exists for companies that survive, and only companies that achieve a certain level of internal unity can survive economic crises.

\section{Unity and Profit}

There are at least two types of confusion that may arise when people try to oversimplify the relationship between unity and profit. The first is to naïvely assume that unity and profit are directly linked. Managers who take this approach think that if employees are more engaged, the company is bound to be more profitable. Numerous studies have shown that unity alone is not enough to generate profit. ${ }^{15}$ The problem is that this approach can lead to opportunistic strategies, in which unity is simply a means of making a profit in the medium term. These strategies fail because, at critical moments, they give priority to short-term economic priorities and end up reducing the company's unity.

The second type of confusion comes from a false dichotomy between unity and profit; this approach assumes there is an inverse relationship between the two. Managers who adopt this approach think that the cost of increasing employee engagement is higher than its benefits and therefore will reduce profit. This way of thinking is also naïve, just as it would be to think that quality and cost are conflicting measures. It is true that quality has a cost, but so does the lack of quality. And these days, only the companies that manage to increase both cost and quality will survive.

\footnotetext{
${ }^{14}$ See: https://www.forbes.com/sites/blakemorgan/2020/03/17/50-ways-companies-are-giving-back-during-the-corona-pandemic/\#7ab6ee724723. [Referenced: 11/9/2020]

${ }^{15}$ J.D. Margolis and H.A. Elfenbein, "Do Well by Doing Good? Don't Count on it," Harvard Business Review, January 2008.
} 


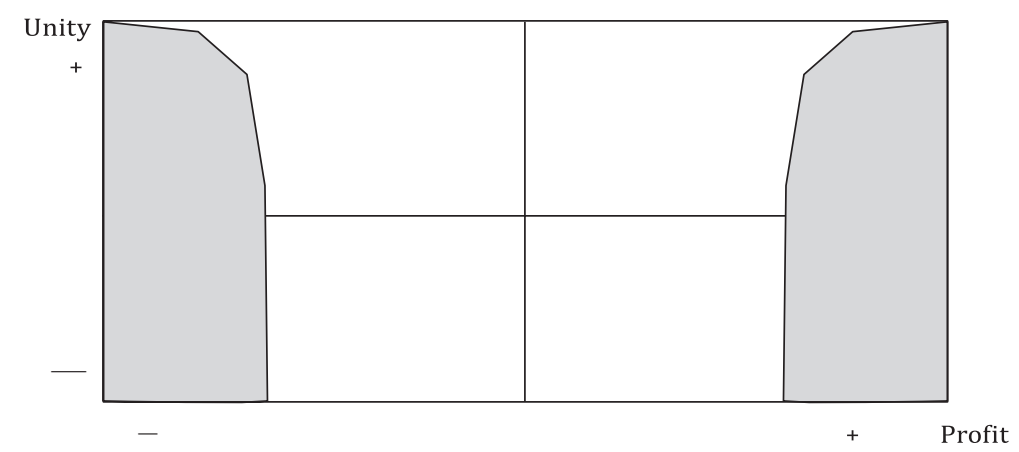

Fig. 1.1 Company diagnosis funnel (CDF)

Similarly, the companies that will survive for years to come are the ones that can improve both unity and profit at the same time.

To avoid oversimplifying, it is better to represent these two dimensions in a two-by-two matrix. Given the way unity, profit and survival are related, the competitive positions available to companies within the matrix are limited. As these constraints are shaped like a funnel, we call this matrix the "company diagnosis funnel" (see Fig. 1.1). In this figure, companies can only survive within the white area, that is, within the funnel. Shaded areas are non-survival areas. The shape of the funnel may vary for different industries and periods, but the basic structure remains the same.

Companies with higher levels of unity may subsist with lower levels of profit, and thus have a better chance of surviving in times of crisis. Companies like Barclays might have found it much more difficult to survive the financial and reputational crisis they suffered in 2008 if they had not had such high unity. To survive the crisis, they focused on three areas: (a) find synergies between purpose and profit; (b) recognizing purpose at the individual level; and (c) overcoming the short-term fear of loss. ${ }^{16}$ As it was, they were able to get past the crisis with a high sense of mission instead of being pulled into a situation of escalating layoffs that

\footnotetext{
${ }^{16}$ A. White, B. Yakis-Douglas, H. Helanummi-Cole and M. Ventresca, "Purpose-Led Organization: 'Saint Antony' Reflects on the Idea of Organizational Purpose, in Principle and Practice," Journal of Management Inquiry, vol. 26, no. 1, 2017, pp. 101-107.
} 
often devolves into what Jeffrey Pfeffer calls the "downward spiral of performance."

On the other side of the funnel, companies with higher unity can earn higher profits, since they have lower transaction costs and monitoring costs, more stability with their key talent and greater creative capacity in the face of challenges. As Pfeffer shows, if they can properly align their managerial practices with the strategy, then companies with a higher level of unity can achieve greater profitability. ${ }^{17}$

A company may move to any part of the funnel but, within that space, its position will not be static. Instead, it will vary dynamically as the company's managers make decisions, its people develop new competencies and the competitive environment changes. For example, the top ten companies in the Fortune ranking in 2012 included Walmart, General Electric, Ford General Motors and Hewlett-Packard. Out of all these, Walmart was the only one to crack the top ten in 2019. If a company makes poor decisions, it will lose ground in both dimensions of the funnel (profit and unity). In other words, a company must constantly make the right decisions both economically and culturally to stay in the same place.

\section{Verification of the Model}

In the 1990s, two Harvard professors, Kotter and Heskett, conducted a study of the relationship between culture strength and business performance. They took 200 companies from 22 different industries and measured the 2 variables over a 10 -year period. The results, using the ROE as an indicator of economic performance, are shown in Fig. 1.2. The bilateral correlation between culture strength and profitability is slightly positive (0.31), but not statistically significant. This study shows that profit and unity are not linearly related.

Nevertheless, the Kotter and Heskett study is not suitable for detecting deeper relationships between the two variables, since the impact of unity on profit is usually seen in the medium term. For this reason, we conducted another empirical study with 220 companies, from which we

\footnotetext{
${ }^{17}$ J. Pfeffer, The Human Equation: Building Profits by Putting People First, Harvard Business School Press, Boston, MA, 1998.
} 


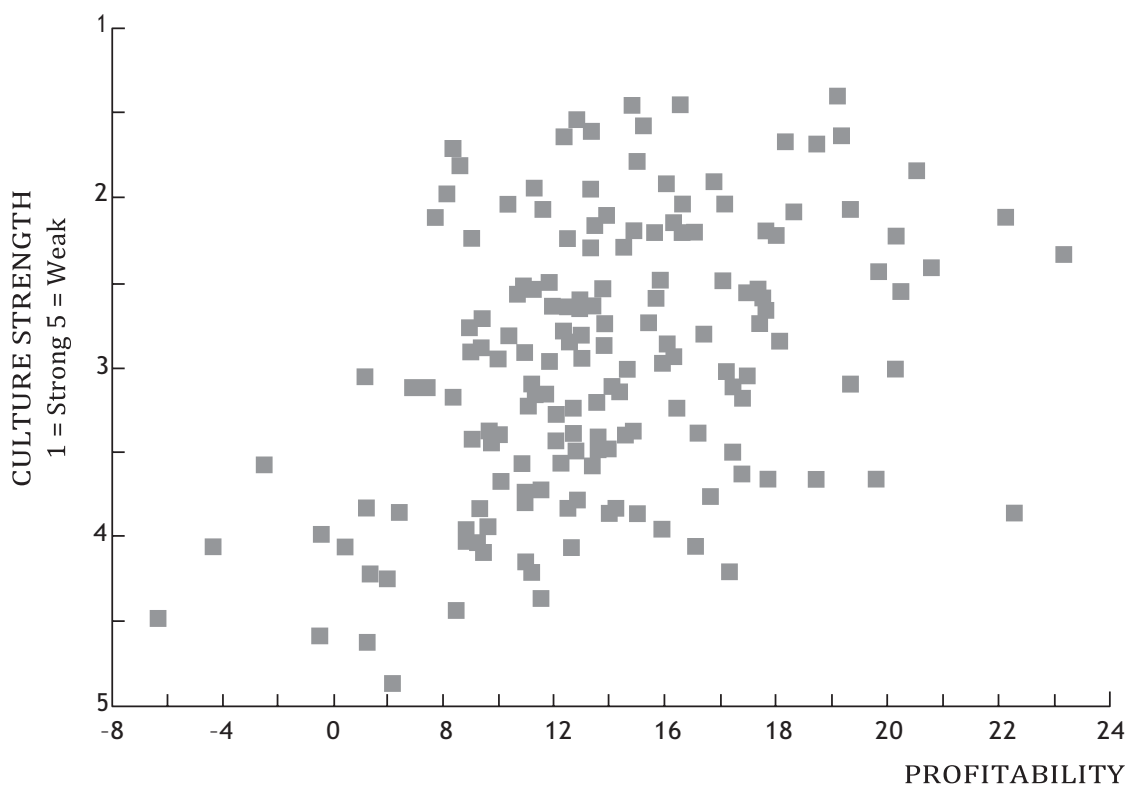

Fig. 1.2 Culture strength and profitability. (Source: Corporate cultures and performance)

chose 76 belonging to the following industries: food, machinery, pharmaceutical, electronics, chemicals and services. In this study, we measured the cultural dimension using unity as our variable. ${ }^{18}$ To measure the profit variable in the medium term, we compared the performance of each company (three-year average ROE) with the industry average. This gave us the normalized value on the matrix's profit scale: positive if the

\footnotetext{
${ }^{18}$ The measure of unity was done using the normalized average of five statements, each scored from 1 (strongly disagree) to 7 (strongly agree):

- The company has a corporate purpose that employees know and are enthusiastic about.

- There are important and familiar company objectives in the medium and long term that are not of a financial nature.

- The company's key contributors fully trust the management.

- There is a high degree of cooperation between all staff.

- People are highly committed to the company's mission and objectives.
}

The measure of unity met the appropriate reliability criteria on a scale of this type, with a Cronbach alpha of 0.84 . 


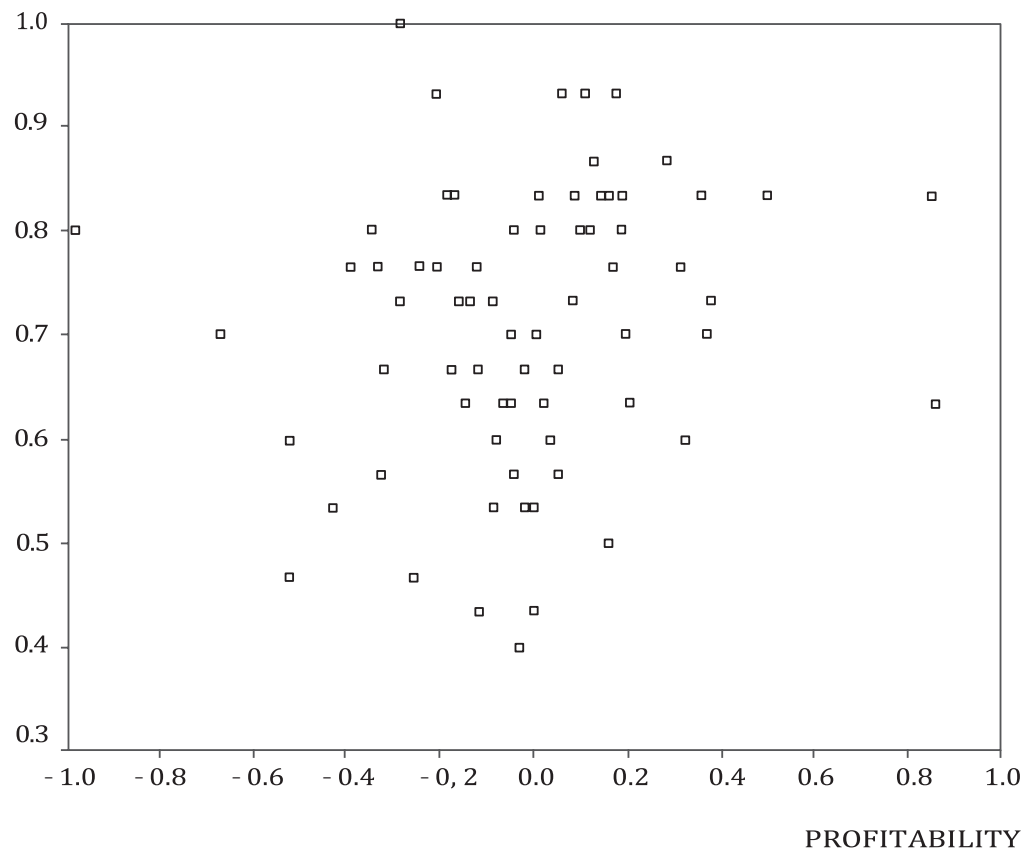

Fig. 1.3 Unity and profit

company's three-year average ROE beat the industry average, negative otherwise. The results of our study are shown in Fig. 1.3.

Again, the bilateral correlation between unity and profitability is slightly positive (0.16), but it is not statistically significant. In turn, the corrections we made in our study allow us to observe the prohibited spaces of the funnel in greater detail: Fig. 1.3 reflects the lower likelihood of companies appearing in the two lower corners, as the model suggests. As unity increases, companies may occupy a larger space within the matrix.

\section{Corporate Culture}

As we have been saying, the vast majority of executive-level decisions impact both profitability and unity. As such, it would be ill-advised to make management decisions based on a single variable. In fact, even the 


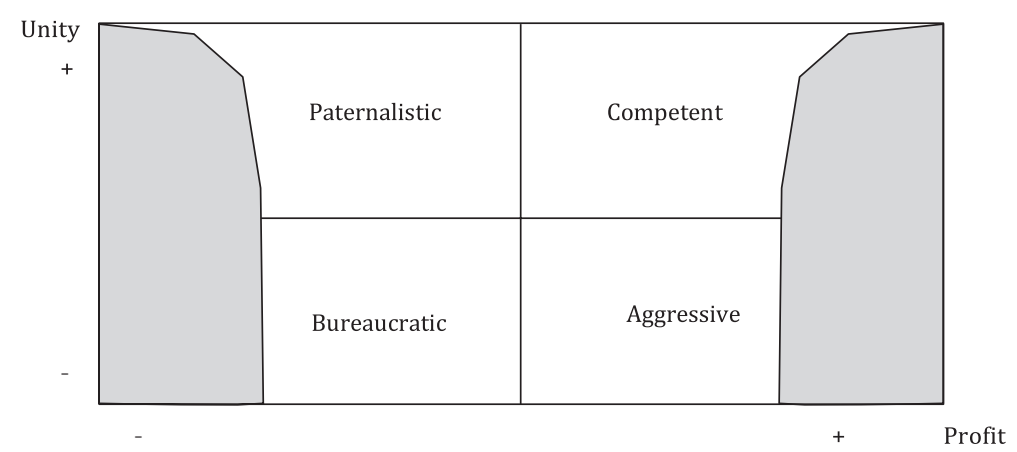

Fig. 1.4 Cultures classification

best strategy alone would be futile without a capable and committed team to implement it. The culture of a given company ultimately comes down to how management decisions are made. We can see four distinct corporate cultures in the funnel in Fig. 1.1: paternalistic, bureaucratic, aggressive and competent. This typology is shown in Fig. 1.4.

The managers of the paternalistic companies make decisions that generate high levels of unity, but not profit. The managers of aggressive companies make decisions that produce reasonable financial results but at the cost of unity. The managers of bureaucratic companies make decisions that generate neither profit nor unity. And the managers of competent companies make decisions that produce high levels of both unity and profitability.

This typology is consistent with Kotter and Heskett's qualitative study of companies situated at the extremes of the matrix. After thoroughly documenting the history and evolution of these companies, and conducting multiple interviews with their managers and employees, they reached the following conclusions:

- Companies with a strong culture and low profitability (paternalistic) were successful in the past. In all cases, poor performance is attributable to the inability to adapt to strong changes in the market or the emergence of new competitors. As the authors define, these companies have a culture defined by past achievements and complacency. Many of those surveyed, when asked what gave their company its strong culture, they said: "We do." 
- Companies with a weak culture and high profitability (aggressive) hold a dominant position in their industry, sheltered by strong entry barriers to new competitors or a legal setup that gives them exceptional competitive advantages. In light of their data, the authors conclude that it is indeed possible to achieve good performance with a weak culture, but only in environments protected by monopoly or oligopoly conditions.

- Companies with a strong culture and high profitability (competent) have two fundamental characteristics that set them apart from the other companies in the sample. First, they have a culture focused on what the authors identify as key stakeholders: customers, shareholders and employees. Second, across the organization they have bosssubordinate relationships based on distributed leadership.

\section{Dynamics of Cultural Development}

As we mentioned before, companies do not remain stagnant in the funnel: unless they do something to prevent it, they lose ground in both dimensions (profit and unity). In other words, just to maintain their position, companies must constantly make the right economic and cultural decisions. This effect would be visually represented in Fig. 1.1 by placing an electric fan in the upper right corner of the matrix. The fan creates a current toward the opposite vertex, that is, toward the quadrant of the bureaucratic enterprise. When a company does not make effort toward the competent zone, it goes into a free fall toward the bureaucratic zone.

Another phenomenon that has become quite common in today's increasingly competitive and global environment is what we might call the "inverted Z" dynamic. We can see it at work in competent companies that become less competitive economically (due to external factors-e.g. technological change, new competition, etc.-or internal ones-e.g. being unable to adapt to change, or being complacent with success). Over time, the company slips into the paternalistic zone, until "steps are taken" to redress the situation. This change can be sudden if the now paternalistic company is acquired by another corporation. 
To illustrate, imagine a German company that has gone from competent to paternalistic, only to be bought out by a US multinational. To revitalize the company, they send over a young executive from New York. Experience shows that the company will most likely shift toward the aggressive area of the funnel. That is because at the company headquarters, the only thing they measure is financial performance, and the easiest thing to progress in this dimension is downward (as we saw with the cost-quality relationship, where the easiest way to improve on cost is to lower the quality).

If the company recovers economically, even if that means sacrificing its unity, the manager will be rewarded, maybe even promoted back to headquarters, where executives capable of pulling such turnarounds tend to congregate (further reinforcing that aggressive style of management). The problem is that the company has fallen into a trap: increasing profit at the cost of unity is not a sustainable proposition. Once unity falls below a certain level, the company can start to lose vital talent: executives and employees who do not accept the cultural change and decide to move on. When this happens, some companies may find their financial performance starts to suffer.

Sometimes, companies need to make painful adjustments in times of crisis. They might run into trouble and lose their sense of direction if, for example, they focus solely on financial performance. Without awareness, it's hard to stop that downward spiral. However, if we have a clear road map, with both dimensions, it's easier to know where we are and where we want to take the organization, even though at some point we will have to head toward the aggressive zone. In such cases, once the moment of crisis has passed, we can regain the lost ground. The company then zigzags "into the wind," toward the competent quadrant.

When decisions are measured by financial performance alone, it is quite difficult in a competitive environment to lead companies into the competent quadrant. As a result, we gradually see more companies flocking to the aggressive quadrant, believing they are doing a great job because they are making money, without thinking about the potential they are leaving on the table by not being truly competent. While at small companies a good executive can direct the organization by simply changing course, at a medium-sized company (and even more so in a large one) the executive needs to rely on adequate systems that also measure and value 
the firm's cultural dimension. These systems act as a second fan, this time in the opposite corner (lower left), pushing the organization into the competent quadrant. These systems are what we call "MBM systems."

\section{Shared Priorities}

There are many examples to illustrate how executives of enduring companies develop a competent culture combining purpose and profit. ${ }^{19}$ For instance, the Tata Group, an Indian industrial conglomerate founded in 1868 by Jamsetji Tata (1839-1904). As stated by Ratan Tata, Jamsetji's great-grandson and former chairman of the company, "Profits are like happiness in that they are a byproduct of other things... companies [...] need sustainability strategies that recognize that you can make money by doing good things rather than the other way around" ${ }^{20}$ With its purpose being to "improve the quality of life of the communities we serve globally," the Tata Group has diversified its activity in industries such as steel, automobiles, chemicals, IT services and hotels, striving to be one of the top corporations in India.

The ability to maintain a competent culture over time is essential for the company's sustainability and represents its greatest source of wealth generation. For this reason, management by missions (MBM) is based on sharing priorities among the different stakeholders. More and more companies look for executives who truly identify with that purpose and are capable of influencing the organization to gain the genuine commitment of their members. For this very reason, the ability to build unity in the organization is an increasingly valued leadership competence. Just as seeking people's maximum potential represented a shift from the twentieth-century executive, the pursuit of unity (ownership and sense of belonging) represents a sea change in modern management.

\footnotetext{
${ }^{19} \mathrm{~J}$. Almandoz, Y. Lee and A. Ribera, "Unleashing the Power of Purpose: 5 Steps to Transform Your Business," IESE Insight, vol. 37, second quarter, 2018, pp. 44-51.

${ }^{20}$ J. Birkinshaw, N.J. Foss and S. Lindenberg, "Combining Purpose with Profits," MIT Sloan Management Review, vol. 55, no. 3, 2014, p. 49.
} 


\section{Rediscovering a Competent Culture}

Jiménez Maña is a business group primarily involved in the distribution of spare automobile parts through a network of franchise locations and corporate-owned stores. Currently, the company has a team of 500 people, with 54 retail outlets and 17 franchises located throughout western Andalucía. During the last decade, the company moved from a competent to an aggressive culture and undertook a big change program to competent culture again.

Manuel Jiménez Maña, the founder's grandson and company CEO, explains: "the company had always been recognized in the market for its great customer relations and highly committed people." Between 1992 and 2007, under Manuel's leadership, the company grew and prospered. However, with that growth, the company was losing its essence. "We had gone from being a small company 'with a soul' to being a large, bureaucratic company," says Manuel.

In 2007, at the onset of the global recession, Manuel was convinced that something had to change, and fast. The diagnosis of his company culture revealed some obvious symptoms: departments working in silos, disconnected from customers, a general lack of communication and constant bottlenecks. After considering different options, they decided to implement management by missions (MBM).

During the initial years of implementation, the company concentrated its efforts on building unity in the organization and rediscovering the company's soul. It began by surveying some customers and representative suppliers, and the entire staff. The objective was to find out what the key stakeholders expected of Jiménez Maña and identify the "positives" that had been undermined in the recent growth process. After collecting the data, various workshops were held to analyze the data and reflect on the company's purpose. In Manuel's words, "the company purpose is defined with and for the stakeholders. They are the ones who tell us why and for whom the company exists. You have to be brave, ask questions and listen to understand the situation, even if you don't like what you hear."

After the first three years of MBM, the organization had experienced a substantial increase in overall unity. Profit also increased slightly, albeit still falling short of the company's true potential (see Fig. 1.5). "At the height of the global recession, the most logical thing would have been to focus on cost cutting, but that's not where we were looking. We focused on our people and on restoring the company's purpose by connecting with our stakeholders. Profit would come later. Purpose comes first, then performance-not the other way around."

Manuel's predictions would soon come true. In 2013, profits were 2 1/2 times higher. The growth would continue in the following years, with the company doubling its size and revenues. "I think that's when we realized 


\section{(continued)}

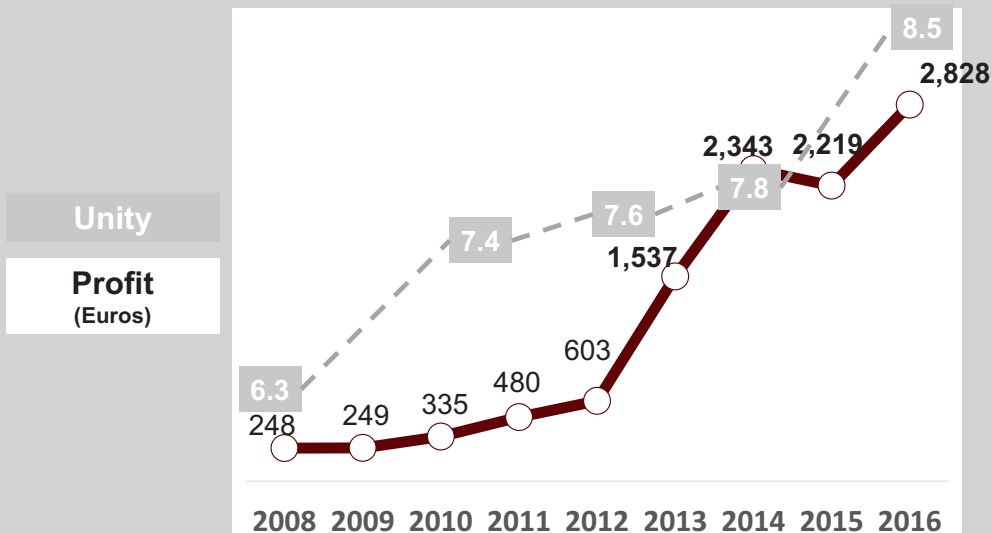

Fig. 1.5 Unity and profit: 2008-2016. The unity data are from a companywide survey given periodically. The profit shown is after taxes

the power of building unity without giving up profit. But we couldn't let up; we had to keep strengthening the unity we had achieved. We weren't about to repeat past mistakes, where positive results got us off course." The company continued deploying its purpose and missions, doubling down on training and development. After a few years, the Jiménez Maña Corporation became a benchmark for companies, both within its sector and beyond.

With the onset of the COVID-19 crisis, the company held true to its commitment. As Manuel explained, "When facing a pandemic like this one, as a business we're concerned about what we may lose, through the "death or illness" of the company: security, money, dreams, relationships, prestige, status... Honestly, we're afraid of losing something tied to what brings happiness to us and to our loved ones (which, by definition, would hurt us, too). Deep down, happiness is what we're all after. And for us, happiness is closely related to our purpose and the service we provide to our stakeholders".

"Ultimately, this goes right in line with how we contribute to the happiness of our stakeholders. If you keep this in mind at all times, you realize that people always come first and that it is the commitment of those people that drives companies forward. Despite having to close for almost two months due to COVID-19, we've remained united, and the recovery has come remarkably fast. And the market has responded very positively, much better than our competitors. In fact, we have gained a lot of new customers. Once again we have seen how unity and profit mutually reinforce one another. But you have to have clear priorities. Crises make you stronger, but only if you stay true to the belief that commitment to a shared purpose comes first." 
Open Access This chapter is licensed under the terms of the Creative Commons Attribution 4.0 International License (http://creativecommons.org/licenses/ by/4.0/), which permits use, sharing, adaptation, distribution and reproduction in any medium or format, as long as you give appropriate credit to the original author(s) and the source, provide a link to the Creative Commons licence and indicate if changes were made.

The images or other third party material in this chapter are included in the chapter's Creative Commons licence, unless indicated otherwise in a credit line to the material. If material is not included in the chapter's Creative Commons licence and your intended use is not permitted by statutory regulation or exceeds the permitted use, you will need to obtain permission directly from the copyright holder.
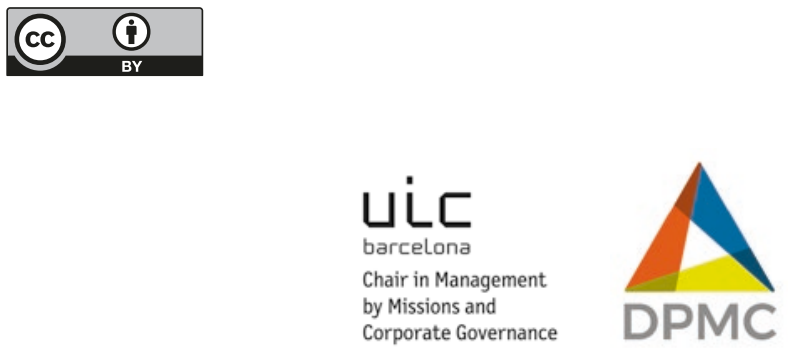